Cronfa - Swansea University Open Access Repository

This is an author produced version of a paper published in :

Annals of Biomedical Engineering

Cronfa URL for this paper:

http://cronfa.swan.ac.uk/Record/cronfa21238

\title{
Paper:
}

Boileau, E., George, C., Parthimos, D., Mitchell, A., Aziz, S. \& Nithiarasu, P. (2015). Synergy Between Intercellular Communication and Intracellular Ca2+ Handling in Arrhythmogenesis. Annals of Biomedical Engineering

http://dx.doi.org/10.1007/s10439-014-1243-x

This article is brought to you by Swansea University. Any person downloading material is agreeing to abide by the terms of the repository licence. Authors are personally responsible for adhering to publisher restrictions or conditions. When uploading content they are required to comply with their publisher agreement and the SHERPA RoMEO database to judge whether or not it is copyright safe to add this version of the paper to this repository. http://www.swansea.ac.uk/iss/researchsupport/cronfa-support/ 


\section{Synergy Between Intercellular Communication and Intracellular Ca2+ Handling in Arrhythmogenesis}

ARTICLE in ANNALS OF BIOMEDICAL ENGINEERING · JANUARY 2015

Impact Factor: $3.23 \cdot$ DOI: 10.1007/s10439-014-1243-x

DOWNLOADS

20
VIEWS

37

6 AUTHORS, INCLUDING:

Christopher H George

Cardiff University

54 PUBLICATIONS $\quad \mathbf{1 , 0 7 4}$ CITATIONS

SEE PROFILE

Alice Mitchell

Cardiff University

4 PUBLICATIONS 0 CITATIONS

SEE PROFILE

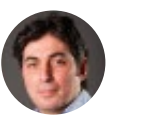

Dimitris Parthimos

Cardiff University

19 PUBLICATIONS 290 CITATIONS

SEE PROFILE

P. Nithiarasu

Swansea University

132 PUBLICATIONS 1,997 CITATIONS

SEE PROFILE 


\title{
Synergy between intercellular communication and intracellular $\mathrm{Ca}^{2+}$ handling in arrhythmogenesis
}

\author{
Etienne Boileau ${ }^{1}$, Christopher H. George ${ }^{2}$, Dimitris Parthimos ${ }^{2}$, Alice N. \\ Mitchell $^{2}$, SABINA AZIZ ${ }^{2}$ AND PERUMAl Nithiarasu ${ }^{1}$ \\ ${ }^{1}$ Biomedical Engineering and Rheology Group, Zienkiewicz Centre for Computational \\ Engineering, Swansea University, Swansea SA2 8PP, United-Kingdom \\ ${ }^{2}$ Cardiff University School of Medicine, Institute of Molecular and Experimental Medicine, \\ Wales Heart Research Institute, Cardiff CF14 4XN, United-Kingdom
}

\begin{abstract}
Calcium is the primary signalling component of excitation-contraction coupling, the process linking electrical excitability of cardiac muscle cells to coordinated contraction of the heart. Understanding $\mathrm{Ca}^{2+}$ handling processes at the cellular level and the role of intercellular communication in the emergence of multicellular synchronization are key aspects in the study of arrhythmias. To probe these mechanisms, we have simulated cellular interactions on large scale arrays that mimic cardiac tissue, and where individual cells are represented by a mathematical model of intracellular $\mathrm{Ca}^{2+}$ dynamics. Theoretical predictions successfully reproduced experimental findings and provide novel insights on the action of two pharmacological agents (ionomycin and verapamil) that modulate $\mathrm{Ca}^{2+}$ signalling pathways via distinct mechanisms. Computational results have demonstrated how transitions between local synchronisation events and large scale wave formation are affected by these agents. Entrainment phenomena are shown to be linked to both intracellular $\mathrm{Ca}^{2+}$ and coupling-specific dynamics in a synergistic manner. The intrinsic variability of the cellular matrix is also shown to affect emergent patterns of rhythmicity, providing insights into the origins of arrhythmogenic $\mathrm{Ca}^{2+}$ perturbations in cardiac tissue in situ.
\end{abstract}

Keywords- Membrane potential, Intra cellular oscillator, Coupling, Synchronisation, Complex dynamical system, Emergence.

\section{INTRODUCTION}

Our present understanding of cardiovascular function, in terms of biological activity at the cellular and tissue level reflects, to a large extent, the simplicity with which we extrapolate information

Address correspondence to: Dimitris Parthimos, Cardiff University School of Medicine, Institute of Molecular and Experimental Medicine, Wales Heart Research Institute, Cardiff CF14 4XN, United-Kingdom, Electronic mail: Parthimos@cardiff.ac.uk 
obtained from (reductionist) experimental approaches into multiple complex processes. ${ }^{4,9}$ Our perspective on cell signalling, for instance, is supported by a reasonably detailed view of multilevel processing pathways, signal integrators and biological oscillators, but our understanding of how these are integrated to coordinate synchronised biological responses in situ remains to be fully defined. ${ }^{4,14,15,28,40}$ As a consequence, there is a clear need to develop new approaches that link investigations of the organisation and coordination of cardiovascular cell and tissue function to the underlying interrelationships between molecules and cellular signalling pathways. ${ }^{6,15-17}$

In the myocardium, the electrical activity largely depends on the coordination of excitatory stimuli as they propagate through the tissue. At the cellular level, excitation-contraction coupling (ECC) - the process linking electrical excitability to physical contraction - involves the opening of surface-membrane $\mathrm{Na}^{+}$channels (depolarisation) which triggers potential-dependent influx of calcium ions $\left(\mathrm{Ca}^{2+}\right)$ through L-type $\mathrm{Ca}^{2+}$ channels (also known as voltage-operated $\mathrm{Ca}^{2+}$ channels, VOCCs) and the subsequent $C \mathrm{C}^{2+}$-induced $\mathrm{Ca}^{2+}$ release (CICR) via ryanodine receptors (RyR). ${ }^{1}$ The ensuing rise in intracellular $\mathrm{Ca}^{2+}$ drives actin-myosin cross-bridge formation and thus myocardial contraction. However, the synchronised contraction of the entire myocardium is dependent on the functional coupling of cardiac myocytes into a well-organised syncytium which can appropriately respond to neurohumoral inputs (e.g. increased adrenergic drive during exercise or periods of stress). ${ }^{38}$ Normal heart function is therefore critically dependent on the complex regulation and encoding of intracellular $\mathrm{Ca}^{2+}$ signals that are synchronised across large regions of the myocardium via mechanical and electrical coupling between cells. ${ }^{5,7,16}$

Accordingly, defects in cellular $\mathrm{Ca}^{2+}$ handling associated with arrhythmogenesis are also subject to dynamical interactions that depend on the state of neighbouring cells, ${ }^{33,37}$ i.e. intercellular communication and, to an extent which remains to be quantified, on differences between cells of the same tissue. Biological variability, sometimes perceived as a lack of predictability, can be an important driving mechanism behind pattern formation in self-organising systems. Cell-to-cell differences may determine patterns on larger scales, arising from a breaking of spatial symmetry, and which may be related to local synchronisation. ${ }^{20,26}$ When a source of 'randomness' is introduced in the system, such phenomena have been shown to arise in model populations. ${ }^{13,18}$ However, in cardiac as well as in other vascular tissue, dissociating the role of intercellular communication from that of the intracellular generative components remains elusive. A combined approach employing mathematical representation of a broad range of experimental observations is therefore required to gain new insights into the phenomena of cardiac tissue synchronisation and the onset of arrhythmogenesis that results from desynchronisation within single cells and across cell populations.

At the sub-cellular and cellular level, theoretical modelling has been useful to describe dynamical features associated with a cell's oscillatory behaviour, ${ }^{27}$ but the structure of such systems is inherently different from that of a population of cells. At a spatial scale larger than the individual myocyte, intercellular connections must be considered to understand how the interactions between cellular CICR and cell-to-cell communication manifest themselves at the tissue level. ${ }^{22}$ Our results show that different patterns of wave formation may arise from the reciprocal influence of individual elements, when they are subject to a certain degree of variability. Using a model of coupled oscillator-based synchronization of $\mathrm{Ca}^{2+}$ oscillations, we investigate how cell variability affects $\mathrm{Ca}^{2+}$ handling, when cells are subject to the action of $\mathrm{Ca}^{2+}$-perturbing pharmacological agents. We use the $\mathrm{Ca}^{2+}$ ionophore ionomycin and verapamil, a drug commonly used for the treatment of arrhythmias. In the present study, we propose a multicellular framework, able to interpret findings from experimental observations at the cellular level, and extrapolate these to the global activity of 
a model layer of cells through complex non linear interactions, electrical connectivity and modes of intercellular synchronization. We first present a comparative analysis, where population results are contrasted with individual cells' behaviour, revealing the variability in the dataset. We then use this concept of variability to justify how intercellular $\mathrm{Ca}^{2+}$ handling and cell-to-cell coupling may be expected to affect the $C \mathrm{Ca}^{2+}$-dependent processes underlying the arrhythmogenic substrate.

\section{MATERIALS AND METHODS}

\section{Experimental Methods}

HL-1 cells are immortalized atrial-derived cells that maintain cardiac cell phenotype (including physical contraction, electrical connectivity and $\mathrm{Ca}^{2+}$ coupling) through serial passage. ${ }^{3}$ HL-1 cells were cultured on gelatin-fibronectin matrices on glass-bottomed coverslips (14mm diameter) in a humidified, $5 \% \mathrm{CO}_{2}$ environment at $37^{\circ} \mathrm{C}$ as described in George et al. ${ }^{8}$ Cells were seeded to achieve an initial density of 30-50\% confluency (700-1000 cells $\mathrm{mm}^{-2}$ - a density at which they are non-contractile and do not exhibit well-organised large-amplitude calcium oscillations) and then subsequently grown to higher densities until they formed spontaneously-contractile monolayers (typically $>2000$ cells $\mathrm{mm}^{-2}$ ) normally day 2-3 days post-seeding. Prior to $\mathrm{Ca}^{2+}$ imaging HL1 cell monolayers, selected on the basis of a defined rate of physical contraction between 0.6 and $2 \mathrm{~Hz}$, were maintained in supplemented Claycomb medium containing ionomycin $(0.1-100 \mathrm{nM}$, from a 1mM stock in dimethyl sulfoxide (DMSO)) or verapamil $(100 \mathrm{nM}-1 \mu \mathrm{M}$, from a $10 \mathrm{mM}$ stock in $\mathrm{H}_{2} \mathrm{O}$ ) for $3 \mathrm{~h}$. HL-1 monolayers which had not been exposed to either drug were used as controls.

\section{Fluorescence Measurements}

Fluo4 is a fluorine-substituted analogue of the widely used fluo3 $\mathrm{Ca}^{2+}$ indicator which has favourable signal intensity and $\mathrm{Ca}^{2+}$-binding kinetic properties. To load HL-1 cells with fluo4 (Life Technologies), control HL-1 monolayers or those that had been incubated with ionomycin or verapamil for $3 \mathrm{~h}$ were switched into supplemented Claycomb media (with or without drug as appropriate) containing $5 \mu \mathrm{M}$ fluo-4-acetoxymethyl ester (AM) (from a $1 \mathrm{mM}$ stock in DMSO) for a further $1 \mathrm{~h}$ at $37^{\circ} \mathrm{C}$. Following this period, coverslips were flooded with $1 \mathrm{ml}$ unsupplemented Claycomb (to avoid fluorescent artefact arising from fetal bovine serum) and left for a further $15 \mathrm{~min}$ to enable de-esterificiation of fluo-4-AM and the liberation of fluorescent 'free' fluo-4 in the cytoplasm of the cells. This protocol exposed the cells to the required concentration of $\mathrm{Ca}^{2+}$-perturbant (ionomycin or verapamil) for a total of $4 \mathrm{~h}$. Coverslips were transferred to the stage of a confocal laser scanning microscope (CLSM) (SP5, Leica Microsystems) fitted with a 63X oil-immersion objective (numerical aperture (NA) of 1.4) maintained at $37^{\circ} \mathrm{C}$ in an environmental chamber. Following stabilization (2-3min) and in order to visualise $\mathrm{Ca}^{2+}$-dependent fluo-4 signals (excitation maximum at 494nm, emission maximum 516nm) cells were illuminated using a 488nm Argon laser at 30\% maximum power and fluorescent outputs (494-550nm) were captured using a photomultiplier tube (PMT). Images were acquired every $36 \mathrm{~ms}$ in a rectangular field of view (FOV) comprising 512x256 pixels (approximately $0.011 \mathrm{~mm}^{2}$, typically 30 cells per FOV). For each coverslip, data corresponding to

$\mathrm{Ca}^{2+}$-dependent fluo-4 signal fluctuations with time were subsequently extracted from 50x50 $\mathrm{\mu m}$ regions of interest (ROI) using Leica LAS-AF software and transposed into csv files. Each ROI corresponded to a single cell within the FOV. 


\section{Mathematical Formulation}

At the ultra-structural level, coupling via CICR between the sarcoplasmic reticulum (SR), intracellular $\mathrm{Ca}^{2+}$ transients and sarcolemmal fluxes constitute one of the fundamental component that underlies ECC. Calcium entering the cell via VOCCs binds to the ryanodine-sensitive SR-Ca ${ }^{2+}$ release channel, allowing rapid $\mathrm{Ca}^{2+}$ efflux from the SR. ${ }^{38}$ Once released into the cytosol, $\mathrm{Ca}^{2+}$ is either pumped out of the cell, or resequestered by the stores, generating requirements for influx of extracellular $\mathrm{Ca}^{2+}$ across the sarcolemma to sustain the oscillatory activity. In the present formulation, each cell is modelled as a $\mathrm{Ca}^{2+}$ oscillator that generates oscillations via CICR. The extracellular influx is provided via $\mathrm{Ca}^{2+}$-permeable non-selective cation channels (NSCCs), VOCCs and reverse mode $\mathrm{Na}^{+}{ }_{-} \mathrm{Ca}^{2+}$ exchange (NCX). Membrane potential is mainly influenced by the balance between $\mathrm{K}^{+}$and $\mathrm{Cl}^{-}$gradients, and by the NCX, depending on whether the exchanger operates in forward or reverse mode. ${ }^{29,30}$

The oscillator is represented by a third-order system of coupled non linear differential equations, as described by Eqs. (A-1). Simulations are produced by numerical integration of this system on a rectangular domain, representing a monolayer of approximately 6000 cells. We use a RungeKutta-Merson algorithm with adaptive time stepping and error control. Unless otherwise sated, all the values of the fixed coefficients employed in the simulations are taken from Parthimos et al. ${ }^{29,30}$ and given in Table 1.

Coupling Electrical and chemical transmission across cells occurs through aggregates of intercellular channels called gap junctions that connect the cytoplasm of adjacent cells in a multicellular population. $\mathrm{Ca}^{2+}$ coupling may effectively arise via intracellular $\mathrm{Ca}^{2+}$ waves or local increases in concentration, or via triggered release by more rapidly diffusing signalling effectors, such as $\mathrm{InsP}_{3} \cdot{ }^{24,38}$ Alteration of gap junction organisation, discontinuities of myocardial architecture, inhomogeneities and/or structural heterogeneity arising from multiple factors may modulate actionpotential conduction (see Rudy ${ }^{32}$ and references therein), and are a consistent feature of heart disease. ${ }^{34}$ In scenarios where the intracellular $\mathrm{Ca}^{2+}$ buffering power is reduced (e.g. arrhythmogenic diseases such as CPVT2) it is plausible that intercellular $\mathrm{Ca}^{2+}$ diffusion may also play a greater role. ${ }^{31}$ The prescribed coupling conditions, as described below, reflect these scenarios to various degrees.

In the model, interactions between cells are determined by the network topology, and a cellspecific parameter that allows each cell to couple to its nearest neighbours via $\mathrm{Ca}^{2+}$ permeability $\left(g_{C a}\right)$ and electrical conductance $\left(g_{z}\right)$. Distinct values of $g_{C a}$ and $g_{z}$ are assigned to each cell, 2,23,25,29 and incorporated in Eqs. (A-1), as described by Eqs. (A-2). We use a Box-Muller transform to generate a pseudo-random Gaussian distribution of each parameter, with a given mean and coefficient of variation, to allow a control over the variability in the conductance states and gapjunctional permeabilities. Mean values of $g_{C a}, g_{z}$ and associated coefficient of variations are given in the text.

\section{RESULTS}

Computational results generated for the entire domain are compared with experimental observations. To validate theoretical predictions in terms of $\mathrm{Ca}^{2+}$ dynamics, information from clusters 
of cells and single cells from 6 different numerical FOV are arbitrarily selected within the computational domain, each containing between 20 and 30 cells, in order to best correspond to the experimental FOV. For most simulations, mean values of the $\mathrm{Ca}^{2+}$ coupling coefficient were in the range $0 \mathrm{~s}^{-1}<g_{C a}<1 \mathrm{~s}^{-1}$, although results were obtained for values of up to $g_{C a}=5 \mathrm{~s}^{-1}$. Electrical coupling is mostly maintained at mean values of either $g_{z}=500 \mathrm{~s}^{-1}$ or $g_{z}=1000 \mathrm{~s}^{-1}$, and all distributions have a coefficient of variation of 0.2 , unless otherwise stated. The effects of varying $\mathrm{Ca}^{2+}$ influx via NSCCs, represented by parameter $A$ in Eq. (A-1a), and via VOCCs, represented by parameter $E_{C a}$ in both Eqs. (A-1a) and (A-1c), were investigated.

\section{Effects of Ionomycin and $\mathrm{Ca}^{2+}$ Entry via NSSCS}

The $\mathrm{Ca}^{2+}$ ionophore ionomycin was employed to raise the intracellular level of $\mathrm{Ca}^{2+}$, primarily via direct $\mathrm{Ca}^{2+}$ influx across the membrane (down its concentration gradient, as extracellular $C \mathrm{Ca}^{2+}$ is approximately $1.3 \mathrm{mM}$ ). Numerically, the action of ionomycin is reproduced by increasing parameter $A$ and thus the $C a^{2+}$ influx in the cytosol via NSCCs. As previously described, the value of $A$ was distributed across the matrix, with three mean values of $A=2.3 \mu \mathrm{M} \mathrm{s}^{-1}, A=2.8 \mu \mathrm{M} \mathrm{s}^{-1}$ and $A=3.3 \mu \mathrm{M} \mathrm{s}^{-1}$. These values extend through the physiological parametric range associated with $\mathrm{Ca}^{2+}$ oscillations. ${ }^{29,30}$

Time series of intracellular $\mathrm{Ca}^{2+}$ concentrations obtained with the mathematical model are extracted for each numerical FOV, as explained above, and selected ROI (each ROI representing an individual cell within a multicellular population) are compared with time series of $\mathrm{Ca}^{2+}$ fluorescence obtained experimentally for increasing concentrations of ionomycin (Fig. 1). Increasing parameter $A$ results in an average increase in cytosolic $\mathrm{Ca}^{2+}$ concentration, but a decrease in the oscillatory amplitude, with increasing variations in frequency (Fig. 2a). It can be observed that the chosen parametric range (numerical simulations) gives rise to a division in the data, where control is in effect contrasted with all other results for increasing concentrations of ionomycin. Results for the complete dataset shown in Fig. 2a also reveal an increase in variability in the experimental amplitudes. Nullcline analysis for single cell dynamics confirmed the large variations in amplitude, but not the changes in oscillatory frequency observed. Indeed, two dimensional phase diagrams depicted in Fig. 3 reveal how an increase in $A$ is associated with a decrease in the size of the limit cycle and an upward translation in the range of working membrane potentials. This discrepancy is an important point of emergent cluster dynamics that is considered further in the Discussion. Variations in $A$ do not influence directly the position of the $y$-nullcline, but equilibria are translated downwards, with a marked contraction of the $\mathrm{Ca}^{2+}$ release phase of the oscillatory mechanism.

\section{Effects of Verapamil and Interaction Between NSSCs and VOCCs}

To understand how cells synchronise their activity, and under which 'conditions of coupling' a global entrainment occurs, we study the interdependence of intracellular $\mathrm{Ca}^{2+}$ and membrane potential, with respect to both NSSCs and VOCCs. Interaction mechanisms between influx via NSSCs and via VOCCs were briefly investigated in Parthimos et al., ${ }^{30}$ where the action of the PLC inhibitor U73122 was modelled as a reduction in coefficient $A$ ( $\mathrm{Ca}^{2+}$ influx via NSSCs), and the action of the VOCC blocker nifedipine was simulated by a reduction in the coefficient $E_{C a}$ $\left(\mathrm{Ca}^{2+}\right.$ entry via VOCCs). Results demonstrated the crucial role of $\mathrm{Ca}^{2+}$ influx in maintaining oscillatory activity. In this study, we use verapamil, a $\mathrm{Ca}^{2+}$ channel antagonist, that has distinct 
effects on cardiac electrophysiology and is used clinically as an antiarrhythmic. ${ }^{19}$ In the mathematical formulation, increasing concentrations of verapamil are modelled as a reduction in $\mathrm{Ca}^{2+}$ entry through VOCCs by decreasing the value of the parameter $E_{C a}$ in Eqs. (A-1a)-(A-1c). Variations are governed by a single parameter value, identical for each cell, and reducing this parameter is consequently done uniformly (no distribution). As for previous simulations, control cases are defined by a reference value. ${ }^{29,30}$

Time series of intracellular $\mathrm{Ca}^{2+}$ obtained with the mathematical model are compared with experimental results for increasing concentrations of verapamil in Fig. 4. Results are extracted for each numerical FOV, as previously described, and selected ROI are compared with time amplitude series of $\mathrm{Ca}^{2+}$ fluorescence. The ability of verapamil to both enhance or suppress oscillations, seen in experimental observations, is reproduced by the numerical results (e.g. differential response of top and bottom traces in Fig. 4 panels (a) and (b), both theoretically and experimentally, after the administration of verapamil). This bi-stable behaviour reveals a close relationship between the two $\mathrm{Ca}^{2+}$ uptake mechanisms investigated here. If $\mathrm{Ca}^{2+}$ uptake via NSCCs is high, reductions in $E_{C a}$ can induce a transition from a small amplitude to a large amplitude limit cycle (light green to yellow in Fig. 5). By contrast, under low NSCC $\mathrm{Ca}^{2+}$ uptake conditions, verapamil can suppress oscillatory activity by shifting the limit cycle onto a stable/non-oscillatory node at high $\left[\mathrm{Ca}^{2+}\right]_{S R}$ values. Results for the complete dataset represented in Fig. 2b show that this behaviour is invariably associated with a reduction in frequency; but depending on the distribution of $A$, amplitude responses to $E_{C a}$ may be different than the one shown in Fig. 2b (left). These scenarios are investigated further as manifestations of emergent synchronization/desynchronization events in the following section.

\section{Dynamics of Large Scale Wave Formation}

The role of pharmacological agents, such as ionomycin, in the emergence of global and local wave patterns has been investigated in an extended array of coupled cells (Fig. 6). Under higher values of $A$, representing increased concentrations of ionomycin (Fig. 6; top to bottom), well defined wave fronts $\left(A=1.3 \mu \mathrm{M} \mathrm{s}^{-1}\right)$ are converted into localised low amplitude fluctuations $\left(A=3.3 \mu \mathrm{M} \mathrm{s}^{-1}\right)$ resembling cardiac fibrillation patterns. This transition is partly due to the fact that high intracellular concentration of $\mathrm{Ca}^{2+}$ will suppress oscillatory activity in segments of the cellular population, and thus introduce a degree of uncoupling within the cellular matrix. The onset of this marked transition from global to local wave activity is dependent on the operating point within the parametric space. Indeed, a different value of $E_{C a}$ shifts the point of transition into fibrillation patterns (Fig. 6), thus illustrating the underlying synergy between the two $\mathrm{Ca}^{2+}$ uptake mechanisms. More specifically, the action of verapamil (reduction of $E_{C a}$ ) can induce both the emergence (lower panels in Fig. 6 from left to right) or the suppression (middle/upper panels in Fig. 6 from left to right) of oscillatory activity, in agreement with experimental observations. The key to this bi-stable response is the underlying availability of $\mathrm{Ca}^{2+}$ (simulated here as different $\mathrm{Ca}^{2+}$ uptake rates on the cellular level, from $A=1.3 \mu \mathrm{M} \mathrm{s}^{-1}$ to $A=3.3 \mu \mathrm{M} \mathrm{s}^{-1}$ ). This overview explains the undesirable contractile side-effect of verapamil as a consequence of reduced $\mathrm{Ca}^{2+}$ influx, and thus impaired CICR.

In order to investigate the role of variability in coupling strength against the variability of individual cells in terms of $\mathrm{Ca}^{2+}$ sequestration capacity, we dispersed simultaneously the distributions of parameters $A$ and $g_{C a}$. At the cellular level, the rate of $\mathrm{Ca}^{2+}$ uptake determines the level of 
$\mathrm{Ca}^{2+}$ sequestration within the stores and, in consequence, the period and amplitude of the primary CICR oscillator. Coupling a large array of such oscillators via membrane potential or $\mathrm{Ca}^{2+}$ fluxes can produce population level dynamics that are dependent, not only on the strength of the coupling, but most importantly on its variability across the array. The emergence of such patterns when the underlying intracellular $(A)$ and intercellular $\left(g_{C a}\right)$ distributions become more pronounced is summarised in Fig. 7. An increase in the coefficient of variation of $A$ (from $\mathrm{CV}_{A}=0.01$ to $\mathrm{CV}_{A}=0.2$ ) convert persistent plane waves of $\mathrm{Ca}^{2+}$ into irregular oscillatory activity, concentrated around a number of 'pacemaking' clusters. When the coefficient of variation of $g_{C a}$ is simultaneously increased $\left(\mathrm{CV}_{g_{C a}}=0.1,0.15\right.$ and 0.3$)$ the wave patterns are further destabilised, highlighting a synergy between intracellular and intercellular $\mathrm{Ca}^{2+}$ handling (Fig. 7). Interestingly, the regularity of the waveforms is least affected for $\mathrm{CV}_{A}=0.01$, even for higher values of $\mathrm{CV}_{g_{C a}}$, suggesting that the system is more robust when the cellular array is in a more uniform state. For a given dispersion of $A$, however, the influence of these 'pacemaking' clusters gradually disappear when its value is increased, showing how a persistent increase in intracellular concentration of $\mathrm{Ca}^{2+}$ may have an effect analogous to cellular uncoupling, as previously mentioned. This can be seen in the transition from top to bottom in Fig. 6, and despite the fact the coupling conditions are identical.

\section{DISCUSSION}

The role of $\mathrm{Ca}^{2+}$ availability and intra- and/or intercellular handling in the onset of coherent oscillatory activity has been studied through mathematical modelling of cellular dynamics across extended arrays of interconnected cells. Theoretical findings were compared to experimental evidence under specific pharmacological interventions. We have employed two pharmacological agents that have established mechanisms of action in modulating main cellular $\mathrm{Ca}^{2+}$ cycling. First, the $\mathrm{Ca}^{2+}$ ionophore ionomycin, that leads to rises in intracellular $\mathrm{Ca}^{2+}$ levels by allowing direct $\mathrm{Ca}^{2+}$ influx across the surface membrane and, to a lesser extent, by activating endogenous $\mathrm{Ca}^{2+}$ entry pathways. Second, verapamil, a L-type voltage-operated channel antagonist that attenuates the $\mathrm{Ca}^{2+}$ influx driven by surface membrane depolarisation, and thus modulates homeostatic $\mathrm{Ca}^{2+}$ influx-efflux balance in spontaneously oscillatory cardiac cells. It is important to note that exposure of cells to these pharmacological agents that perturb intracellular $\mathrm{Ca}^{2+}$ handling via different pathways would be expected to manifest as altered intercellular $\mathrm{Ca}^{2+}$ dynamics. Moreover, due to the interlinked nature of cellular $\mathrm{Ca}^{2+}$ signalling pathways, both ionomycin and verapamil would be expected to evoke compensatory adaptations in $\mathrm{Ca}^{2+}$ cycling.

Experimental and theoretical results on the action of ionomycin have demonstrated a tendency to reduce oscillatory frequency of a nearly harmonic signal and unmask complex dynamical features such as period doubling and mixed mode oscillations. Such findings conform with long existing theories that arrhythmogenesis can be regarded as a dynamical process. ${ }^{10,12}$ The most important feature of the action of ionomycin is the reduction of oscillatory frequency observed experimentally (Fig. 1 and Fig. 2). This is contrary to theoretical results for single cell dynamics, illustrated by the nullcline and limit cycle analysis in Fig. 3, and highlights the point that $\mathrm{Ca}^{2+}$ handling in an extended array of interconnected cells can introduce coupling-specific dynamics. The evolution of oscillatory activity presented in Fig. 1 is due to the transition of individual cellular dynamics from a non-oscillatory node to slow/large amplitude to fast/low amplitude oscillations that are eventually suppressed (see limit cycle transition in Fig. 3). Increased intracellular $\mathrm{Ca}^{2+}$ con- 
centrations across the array will, therefore, suppress the faster cells while simultaneously initiate slow/large amplitude oscillations in previously quiescent cells that subsequently dominate the oscillatory profile of the extended matrix. This effective spatial heterogeneity may lead to variability in signals (both within and between cells) and thus predispose to intercellular desynchronization. Indeed simulations demonstrate that different groups of oscillators dissociate into coherent and incoherent regions, resulting in desynchronisation of the entire population.

Although similar in nature, the effect of verapamil on reducing cellular $\mathrm{Ca}^{2+}$ uptake has been long associated with a bi-stable response, due to its ability to selectively enhance or suppress oscillatory activity. This effect is indeed illustrated in Fig. 4, where two apparently similar control signals (first and third row) are differentially enhanced or suppressed. This result, matched by the numerical simulations, has been previously attributed to the available $\mathrm{Ca}^{2+}$ levels within individual cells, thus providing a direct link between NSCC and VOCC influx. ${ }^{29,30}$ A further hypothesis on the impact of verapamil on this scheme is based on its potency as a hERG-K+ channel blocker. ${ }^{43}$ Such an effect will lead to cellular depolarisation, which in turn activates VOCCs influx, thus negating part of the action of verapamil. Although this further assumption is not necessary for producing the bi-stable response associated with VOCC blockage, the effect on membrane potential remains central as illustrated in Fig. 5. Although not shown, effects of varying the $g_{z}$ distribution are less important. They reflect on the oscillatory patterns, and can be attributed mainly to the role of VOCCs, as $\mathrm{Ca}^{2+}$ influx through NSCCs is not directly associated with membrane potential changes (see nullcline analysis in Fig. 3).

To elucidate the role of gap junctions in mediating $\mathrm{ECC}$, we have investigated how variability in the distribution of $g_{C a}$ is affected by the intracellular components of $\mathrm{Ca}^{2+}$ handling, represented by the distribution of the parameter $A\left(\mathrm{Ca}^{2+}\right.$ entry via NSCCs). Increase in the coefficient of variation of parameters $A\left(\mathrm{CV}_{A}\right)$ and $g_{C a}\left(\mathrm{CV}_{g_{C a}}\right)$ is physiologically equivalent to 'thinning' the substrate matrix in a manner similar to that resulting from muscle pathology associated with apoptosis (heart failure) or muscular trauma (myocardial infarction). Importantly the two coefficients mimic such effects in dynamically distinct ways. As a consequence, when the range of $\mathrm{Ca}^{2+}$ uptake by individual cells is extended (increased $\mathrm{CV}_{A}$ ), a subset of cells will become quiescent due to low $\mathrm{Ca}^{2+}$ availability, whereas a second subset will reach a non-oscillatory state due to over stimulation by high influx of $\mathrm{Ca}^{2+}$. Individual cells will respond differentially to intracellular feedback mechanisms. Populations of cells will therefore remain non-responsive to intercellular stimulation, in effect thinning the cellular array. By comparison, increasing $\mathrm{CV}_{g_{C a}}$ can be thought of as provoking regional changes in the quantity and organisation of gap junctions. As seen in Fig. 7, regular oscillatory activity can be disturbed by increasing either coefficients of variation. Interestingly, when the cellular matrix is more uniform $\left(\mathrm{CV}_{A}=0.01\right)$ an increase in $\mathrm{CV}_{g_{C a}}$ does not disturb the established wave forms. The findings summarised in Fig. 7 suggest a synergy between the $A$ and $g_{C a}$ distributions, i.e. between the intracellular and intercellular components of $\mathrm{Ca}^{2+}$ handling. Such a synergy, which has not been fully explored in the present context, may provide subtle insights into the emergence of arrhythmic states in cardiac tissue.

In summary, we have shown how coupling in an extended array of cells can introduce dynamical interactions that are significantly different than those conjectured by single-cell models. Our observations support the hypothesis that $\mathrm{Ca}^{2+}$ movements at the sub-cellular and cellular level may coordinate $C \mathrm{a}^{2+}$ events at a larger scale to produce global responses. These are dependent on properties of the cellular matrix, as may be reflected by varying the dispersion of distributions of the parameters $A\left(\mathrm{Ca}^{2+}\right.$ entry via non-selective cation channels) and $g_{C a}$ (representing $\mathrm{Ca}^{2+}$ per- 
meability/diffusion under various dysfunctional states). As suggested by previous experimental evidence, $\mathrm{Ca}^{2+}$ handling and cell-to-cell coupling are closely related, and such variations would indeed be expected to influence the $\mathrm{Ca}^{2+}$-dependent processes underlying excitation-contraction coupling and the arrhythmogenic substrate. ${ }^{21,35,36,39,41,42}$

\section{ACKNOWLEDGEMENT}

This work was partly supported by grants from the British Heart Foundation (FS/09/028/27602, FS/06/082/21723), Heart Research UK (RG2559), Wellcome Trust (094219/Z/10/Z), and the Cardiff Partnership Fund. The authors also acknowledge the financial support provided by the Sêr Cymru National Research Network in Advanced Engineering and Materials.

\section{REFERENCES}

1 Bers, D. M. Cardiac excitation-contraction coupling. Nature 415:198-205, 2002.

2 Christ, G. J., D. C. Spray, M. El-Sabban, L. K. Moore , and P. R. Brink. Gap Junctions in Vascular Tissues. Evaluating the Role of Intercellular Communication in the Modulation of Vasomotor Tone. Circ. Res. 79:631-646, 1996.

3 Claycomb, W. C., N. A. Lanson, B. S. Stallworth, D. B. Egeland, J. B. Delcarpio, A. Bahinski, and N. J. Izzo Jr. HL-1 cells: a cardiac muscle cell line that contracts and retains phenotypic characteristics of the adult cardiomyocyte. Proc. Natl. Acad. Sci. U.S.A. 95:2979-2984, 1998.

4 Dehmelt, L., and P. I. H. Bastiaens. Spatial organization of intracellular communication: insights from imaging. Nat. Rev. Mol. Cell. Biol. 11:440-452, 2010.

5 Dhillon, P. S., R. Gray, P. Kojodjojo, R. Jabr, R. Chowdhury, C. H. Fry, and N. S. Peters. Relationship between gap-junctional conductance and conduction velocity in mammalian myocardium. Circ. Arrhythm. Electrophysiol. 6:1208-1214, 2013.

6 Drikakis, D., J. Lechuga, and S. Pal. Effects of shock waves on biological membranes: a molecular dynamics study. J. Comput. Theor. Nanos. 6:1437-1442, 2009.

7 Falcke, M. Reading the patterns in living cells - the physics of Ca2+ signaling. Adv. Phys. 53:255-440, 2004.

8 George, C. H., G. V. Higgs, and F. A. Lai. Ryanodine receptor mutations associated with stressinduced ventricular tachycardia mediate increased calcium release in stimulated cardiomyocytes. Circ. Res. 93:531-540, 2003.

9 George, C. H., D. Parthimos, and N. C. Silvester. A network-oriented perspective on cardiac calcium signaling. Am. J. Physiol. Cell Physiol. 303:C897-C910, 2012.

10 Glass L. Synchronization and rhythmic processes in physiology. Nature 410:277-284, 2001.

11 Gokina, N. I., R. D. Bevan, C. L. Walters, and J. A. Bevan. Electrical activity underlying rhythmic contraction in human pial arteries. Circ. Res. 78:148-153, 1996. 
12 Guevara M. R., L. Glass, and A. Shrier. Phase locking, period doubling bifurcations and irregular dynamics in periodically stimulated cardiac cells. Science 214:1350-1353, 1981.

13 Jacobsen, J. C., C. Aalkjaer, V. V Matchkov, H. Nilsson, J. J. Freiberg, and N. H. HolsteinRathlou. Heterogeneity and weak coupling may explain the synchronization characteristics of cells in the arterial wall. Philos. Trans. A. Math. Phys. Eng. Sci. 366:3483-3502, 2008.

14 Jordan, J.D., E. M. Landau, and R. Iyengar. Signaling networks: the origins of cellular multitasking. Cell 103:193-200, 2000.

15 Kholodenko, B., M. B. Yaffe, and W. Kolch. Computational approaches for analyzing information flow in biological networks. Science signaling 5:re1, 2012.

16 Kim, J.-R., D. Shin, S. H. Jung, P. Heslop-Harrison, and K.-H. Cho. A design principle underlying the synchronization of oscillations in cellular systems. J. Cell Sci. 123:537-543, 2010.

17 Kitano, H. Grand challenges in systems physiology. Front. Physiol. 1:3, 2010.

18 Koenigsberger, M, R. Sauser, and J.-J. Meister. Emergent properties of electrically coupled smooth muscle cells. Bull. Math. Biol. 67:1253-1272, 2005.

19 Krikler, D. M. Verapamil in arrhythmia. Br J Clin Pharmacol. 21(Suppl 2):1835:1895, 1986.

20 Kurz, F.T., M. A. Aon, B. O'Rourke, and A. A. Armoundas. Spatio-temporal oscillations of individual mitochondria in cardiac mycocytes reveal modulation of synchronized mitochondrial clusters. Proc. Natl. Acad. Sci. USA 107:14315-14320, 2010.

21 Lakatta, E.G., V. A. Maltsev, K. Y. Bogdanov, M. D. Stern, and T. M. Vinogradova. Cyclic variation of intracellular calcium: a critical factor for cardiac pacemaker cell dominance. Circ. Res. 92:E45-E50, 2003.

22 Lee, Y.-S., O. Z. Liu, and E. A. Sobie. Decoding myocardial Ca2+ signals across multiple spatial scales: A role for sensitivity analysis. J. Mol. Cell. Cardiol. 58:92-99, 2003.

23 Li, X., and J. M. Simard. Multiple Connexins Form Gap Junction Channels in Rat Basilar Artery Smooth Muscle Cells. Circ. Res. 84:1277-1284, 1999.

24 Miura, M., P. A. Boyden, H. E. ter Keurs. Calcium waves during triggered propagated contractions in intact trabeculae. Am. J.Physiol. 274:H266-H276, 1998.

25 Moreno, A. P., M. B. Rook, G. L. Fishman, and D. C. Spray. Gap Junction Channels: Distinct Voltage-Sensitive and -Insensitive Conductance States. Biophys. J. 67:113-119, 1994.

26 Nakamura, N., T. Yamazawa, Y. Okubo, and M. Iino. Temporal switching and cell-to-cell variability in Ca2+ release activity in mammalian cells. Mol. Syst. Biol. 5:247, 2009.

27 Nivala, M., C. Y. Ko, M. Nivala, J. M. Weiss, and Z. Qu. Criticality in Intracellular Calcium Signaling in Cardiac Myocytes. Biophys. J. 102:2433-2442, 2012. 
28 Novak, B., and J. J. Tyson. Design principles of biochemical oscillators. Nat. Rev. Mol. Cell Biol. 9:981-991, 2008.

29 Parthimos, D., D. H. Edwards, and T. M. Griffith. Minimal model of arterial chaos generated by coupled intracellular and membrane Ca2+ oscillators. Am. J. Physiol. Heart Circ. Physiol. 46:H1119-H1144, 1999.

30 Parthimos, D., R. E. Haddock, C. E. Hill, and T. Griffith. Dynamics of a three-variable nonlinear model of vasomotion: comparison of theory and experiment. Biophys. J. 93:1534-1556, 2007.

31 Postma, A.V., I. Denjoy, T. M. Hoorntje, J. M. Lupoglazoff, A. Da Costa, P. Sebillon, M. M. A. M. Mannens, A. A. M. Wilde, and P. Guicheney. Absence of calsequestrin 2 causes severe forms of catecholaminergic polymorphic ventricular tachycardia. Circ. Res. 91:E21-E26, 2002.

32 Rudy, Y. Conductive Bridges in Cardiac Tissue. A Beneficial Role or an Arrhythmogenic Substrate? Circ. Res. 94:709-711, 2004.

33 Scoote, M., A. J. Williams. Myocardial calcium signalling and arrhythmia pathogenesis. Biochem. Biophys. Res. Commun. 322:1286-1309, 2004.

34 Severs, N. J., S. R. Coppen, E. Dupont, H. I. Yeh, Y. S. Ko, and T. Matsushita. Gap junction alterations in human cardiac disease. Cardiovasc. Res. 62:368-377, 2004.

35 Stern, M.D., L. A. Maltseva, M. Juhaszova, S. J. Sollott, E. G. Lakatta, and V. A. Maltsev. Hierarchical clustering of ryanodine receptors enables emergence of a calcium clock in sinoatrial node cells. J. Gen. Physiol. 143:577-604, 2014.

36 Roell, W., T. Lewalter, P. Sasse, Y. N. Tallini,B. R. Choi, M. Breithart, R. Doran, U. M. Becher, S. M. Hwang, T. Bostani, J. von Maltzahn, A. Hofmann, S. Reining, B. Eiberger, B. Gabris, A. Pfeifer, A. Welz, K. Willecke, G. Salama, J. W. Schrickel, M. I. Kotlikoff, and B. K. Fleischmann. Engraftment of connexin 43-expressing cells prevents post-infarct arrhythmia. Nature 450:819-826, 2007.

37 Shaw, R. M., and Y. Rudy. Ionic Mechanisms of Propagation in Cardiac Tissue. Roles of the Sodium and L-type Calcium Currents During Reduced Excitability and Decreased Gap Junction Coupling. Circ. Res. 81:727-741, 1997.

38 Ter Keurs, H. E. D. J. and P. A. Boyden. Calcium and arrhythmogenesis. Physiol. Rev. 87:457506, 2007.

39 Tribulova, N., S. Seki, J. Radosinska, P. Kaplan, E. Babusikova, V. Knezl, and S. Mochizuki. Myocardial Ca2+ handling and cell-to-cell coupling, key factors in prevention of sudden cardiac death. Cana. J. Physiol. Pharm. 87:1120-1129, 2009.

40 Tyson, J.J., K. C. Chen, and B. Novak. Sniffers, buzzers, toggles and blinkers: dynamics of regulatory and signaling pathways in the cell. Curr. Opin. Cell Biol. 15:221-231, 2003.

41 Weiss, J.N. How does falling out of phase of intracellular calcium and action potentials across the heart's wall spell the beginning of chaos for the heart? Dialog. Cardiovasc. Med. 15:302$310,2010$. 
42 Weiss, J.N., M. Nivala, A. Garfinkel, and Z. Qu. Alternans and arrrhythmias: from cell to heart. Circ. Res. 108:98-112, 2011.

43 Zhang S., Z. Zhou, Q. Gong, J. C. Makielski, and C. T. January. Mechanisms of block and identification of the verapamil binding domain to HEGR potassium channels. Circ. Res. 84:989998, 1999. 


\section{List of Figures}

1 Comparison of numerical results and experimental traces for increasing concentrations of ionomycin. (a) Control (no drug), (b) 0.1-1nM and (c) 10nM-100nM. For each figure, the left panel corresponds to the time amplitude series of $\mathrm{Ca}^{2+}$ fluorescence, obtained from the experiments. The right panel (grey lines) represent the time amplitude series of $\mathrm{Ca}^{2+}$ oscillations obtained with the mathematical model. The mean $\left[\mathrm{Ca}^{2+}\right]_{i}$ value (in $\mu \mathrm{M}$ ) in each scenario is given on the right hand side of each trace. . . . . . . . . . . . . . . . . . . . 15

2 Comparative results for the complete experimental (left coloured boxes) and numerical (right boxes) dataset, showing relative amplitude and oscillatory frequency $(\mathrm{Hz})$ for (a) ionomycin and (b) verapamil. The relative amplitude describes the fold difference between the peak $\mathrm{Ca}^{2+}$ oscillation amplitude and the basal $\mathrm{Ca}^{2+}$ signal. Lower/upper fences extend at twice the interquartile range of the data below/above the first/third quartile respectively. . . . . . . . . . . . . . . . 16

3 Nullcline analysis of the action of varying $\mathrm{Ca}^{2+}$ influx via NSSCs. Phase diagram for changes in the parameter $A$, with (a) membrane potential held constant at $-30 \mathrm{mV}$, and (b) $\left[\mathrm{Ca}^{2+}\right]_{S R}$ held constant at $1 \mu \mathrm{M}$. Dark green colour is for $A=2.3 \mu \mathrm{M} \mathrm{s}^{-1}$, light green colour for $A=2.8 \mu \mathrm{M} \mathrm{s}^{-1}$, and yellow colour for $A=3.3 \mu \mathrm{M} \mathrm{s}^{-1}$. $x$-nullclines $\left(\left[\mathrm{Ca}^{2+}\right]_{i}\right)$ are coloured according to the same pattern. Results are presented for an arbitrary cell within the computational domain, and take into account coupling conditions. Assorted phase plots and equilibria are obtained for different cells, but all present the same generic characteristics. . . . . . . . . . . .

Comparison of numerical results and experimental traces for increasing concentrations of verapamil. (a) Control (no drug) and (b) $100 \mathrm{nM}-1 \mu \mathrm{M}$. For each figure, the left panel corresponds to the time amplitude series of $\mathrm{Ca}^{2+}$ fluorescence, obtained from the experiments. The right panel (grey lines) represent the time amplitude series of $\mathrm{Ca}^{2+}$ oscillations obtained with the mathematical model. The mean $\left[\mathrm{Ca}^{2+}\right]_{i}$ value (in $\mu \mathrm{M}$ ) in each scenario is given on the right hand side of each trace. Nullcline analysis of the action of $\mathrm{Ca}^{2+}$ influx via VOCCs. Phase diagram for changes in the parameter $E_{C a}$ with (a) membrane potential held constant at $-30 \mathrm{mV}$, and (b) $\left[\mathrm{Ca}^{2+}\right]_{S R}$ held constant at $1 \mu \mathrm{M}$. From dark green to yellow $E_{C a}=18 \mu \mathrm{M} \mathrm{V}^{-1} \mathrm{~s}^{-1}$, $E_{C a}=12 \mu \mathrm{MV}^{-1} \mathrm{~s}^{-1}$, and $E_{C a}=2 \mu \mathrm{MV}^{-1} \mathrm{~s}^{-1}$. $x$-nullclines $\left(\left[\mathrm{Ca}^{2+}\right]_{i}\right)$ are coloured according to the same pattern. Arrow shows the transition towards a stable equilibrium as $E_{C a}$ is further reduced. Results are presented for an arbitrary cell within the computational domain, and take into account coupling conditions. Assorted phase plots and equilibria are obtained for different cells, but all present the same generic characteristics. . . . . . . . . . . . . .

Effect of simultaneously varying $A$ (reproducing increasing concentrations of ionomycin) and $E_{C a}$ (reproducing increasing concentrations of verapamil). Transition starts from a lower value of $A=1.3 \mu \mathrm{M} \mathrm{s}^{-1}$. Coefficient of variations $\left(\mathrm{CV}_{A}\right.$ and $\left.\mathrm{CV}_{g_{C a}}\right)$ and coupling conditions are identical for all figures. Red colour represent $\left[\mathrm{Ca}^{2+}\right]_{i}$, green the stored concentration $\left[\mathrm{Ca}^{2+}\right]_{S R}$, and blue the membrane potential. A purple/magenta colour is seen where red and blue strengths are equal, and therefore indicative of membrane depolarisation and high $\mathrm{Ca}^{2+}$ influx. . . . . . . 18 
7 Effect of simultaneously varying the coefficient of variation for the $A$ distribution $\left(\mathrm{CV}_{A}\right)$ and for the $g_{C a}$ distribution $\left(\mathrm{CV}_{g_{C a}}\right)$. The mean value of $A$ is identical for all figures, and coupling is maintained at the same level. Colour coding as in Fig. 6 
(a) Control

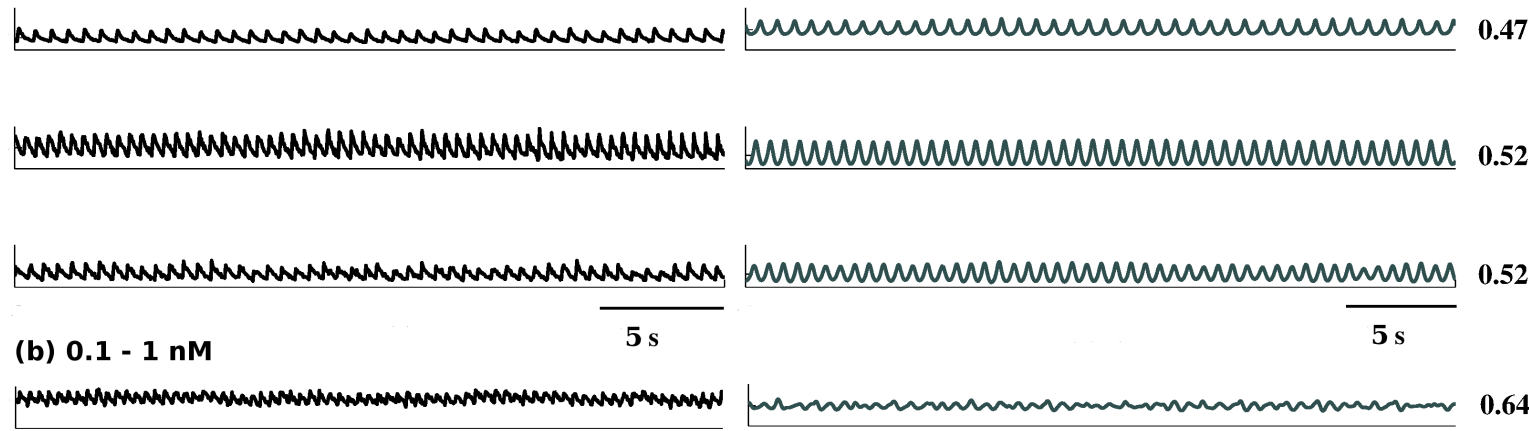

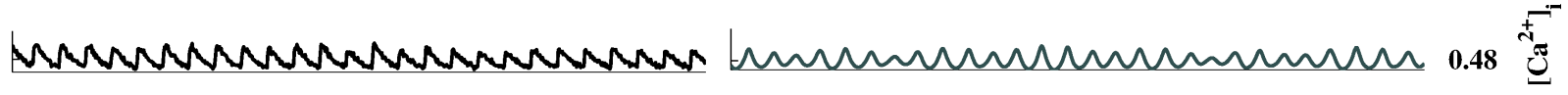

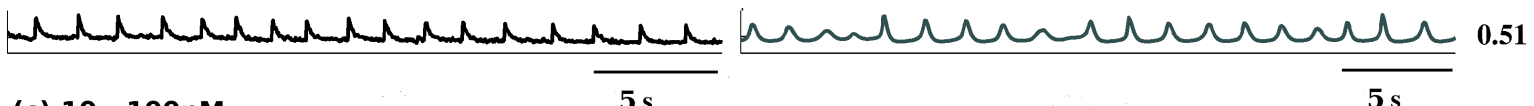

(c) $10-100 \mathrm{nM}$

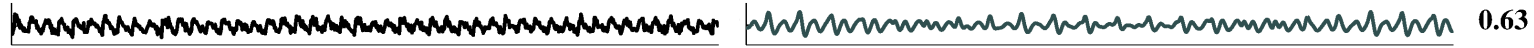
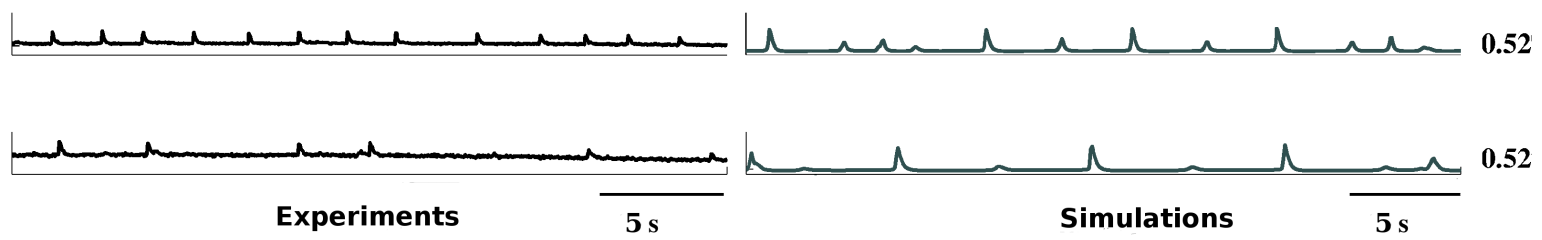

FIGURE 1. Comparison of numerical results and experimental traces for increasing concentrations of ionomycin. (a) Control (no drug), (b) $0.1-1 \mathrm{~nm}$ and (c) 10nM-100nM. For each figure, the left panel corresponds to the time amplitude series of $\mathrm{Ca}^{2+}$ fluorescence, obtained from the experiments. The right panel (grey lines) represent the time amplitude series of $\mathrm{Ca}^{2+}$ oscillations obtained with the mathematical model. The mean $\left[\mathrm{Ca}^{2+}\right]_{i}$ value (in $\mu \mathrm{M}$ ) in each scenario is given on the right hand side of each trace. 

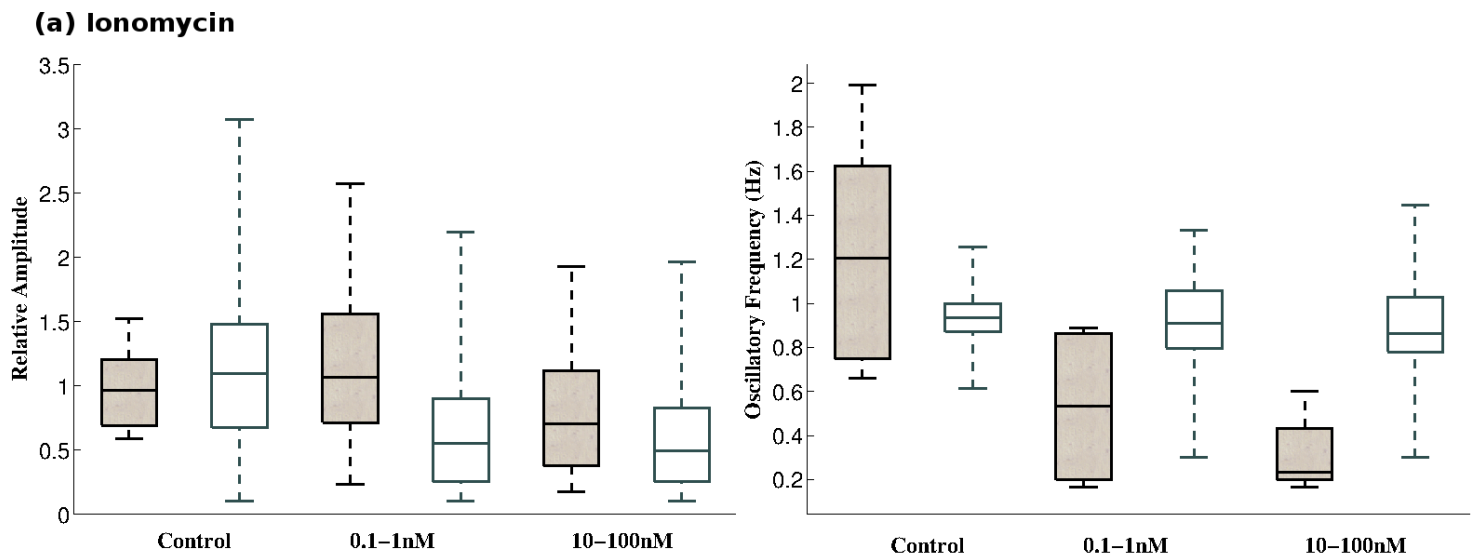

(b) Verapamil
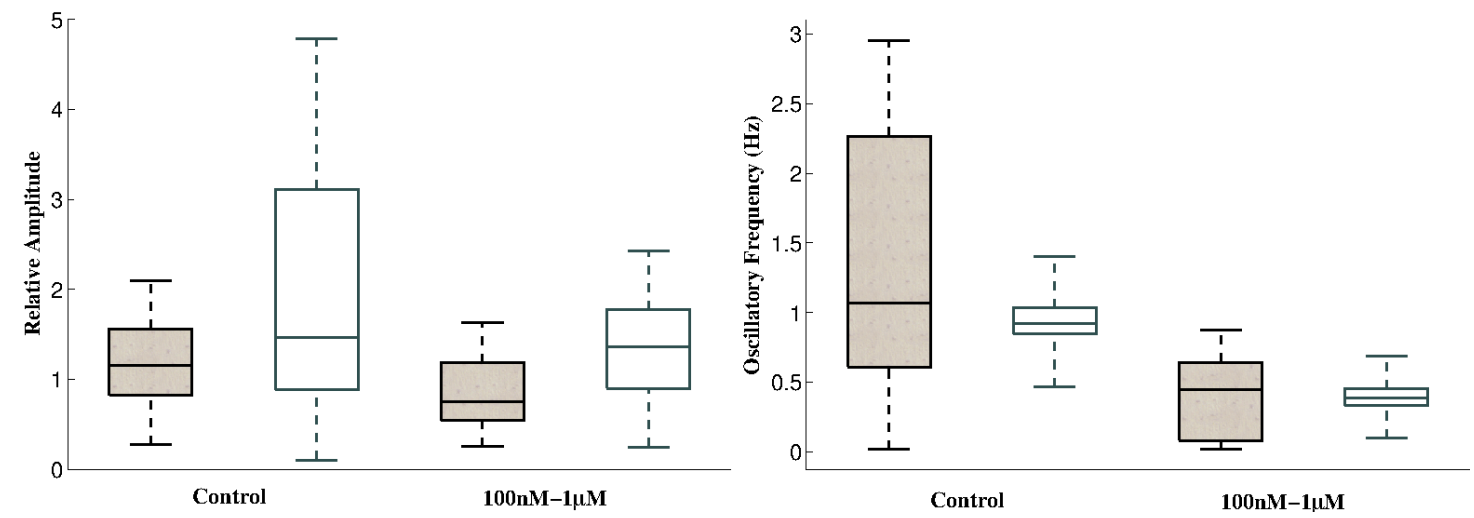

FIGURE 2. Comparative results for the complete experimental (left coloured boxes) and numerical (right boxes) dataset, showing relative amplitude and oscillatory frequency $(\mathrm{Hz})$ for (a) ionomycin and (b) verapamil. The relative amplitude describes the fold difference between the peak $\mathrm{Ca}^{2+}$ oscillation amplitude and the basal $\mathrm{Ca}^{2+}$ signal. Lower/upper fences extend at twice the interquartile range of the data below/above the first/third quartile respectively. 
(a)

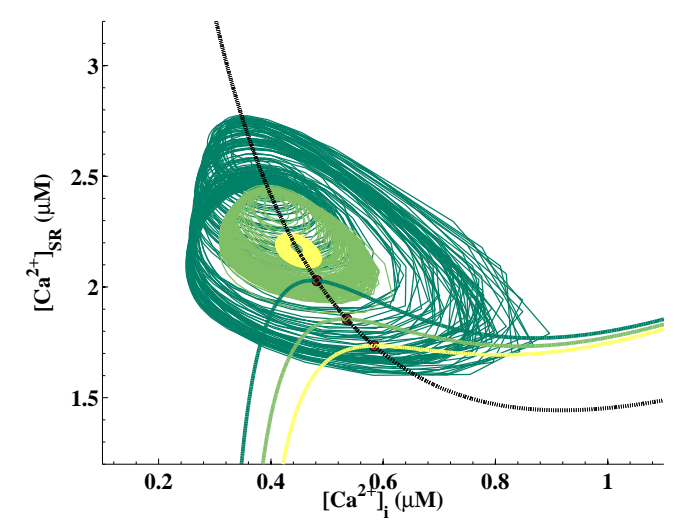

(b)

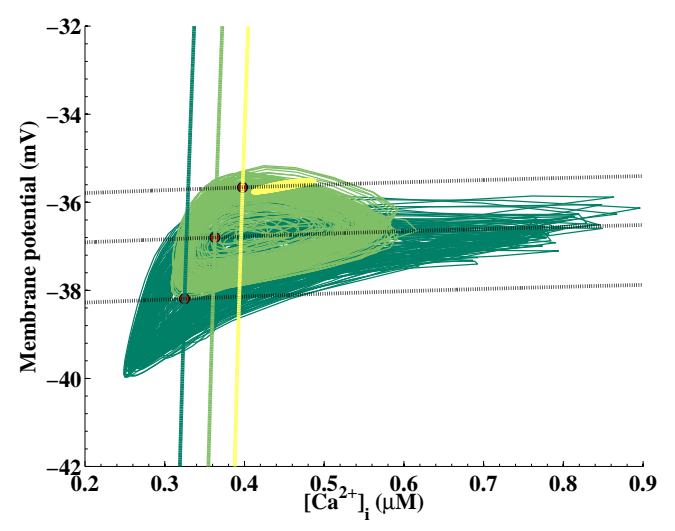

FIGURE 3. Nullcline analysis of the action of varying $\mathrm{Ca}^{2+}$ influx via NSSCs. Phase diagram for changes in the parameter $A$, with (a) membrane potential held constant at $-30 \mathrm{mV}$, and (b) $\left[\mathrm{Ca}^{2+}\right]_{S R}$ held constant at $1 \mu \mathrm{M}$. Dark green colour is for $A=2.3 \mu \mathrm{M} \mathrm{s}^{-1}$, light green colour for $A=2.8 \mu \mathrm{M} \mathrm{s}^{-1}$, and yellow colour for $A=3.3 \mu \mathrm{M} \mathrm{s}^{-1} \cdot x$-nullclines $\left(\left[\mathrm{Ca}^{2+}\right]_{i}\right)$ are coloured according to the same pattern. Results are presented for an arbitrary cell within the computational domain, and take into account coupling conditions. Assorted phase plots and equilibria are obtained for different cells, but all present the same generic characteristics.

(a) Control

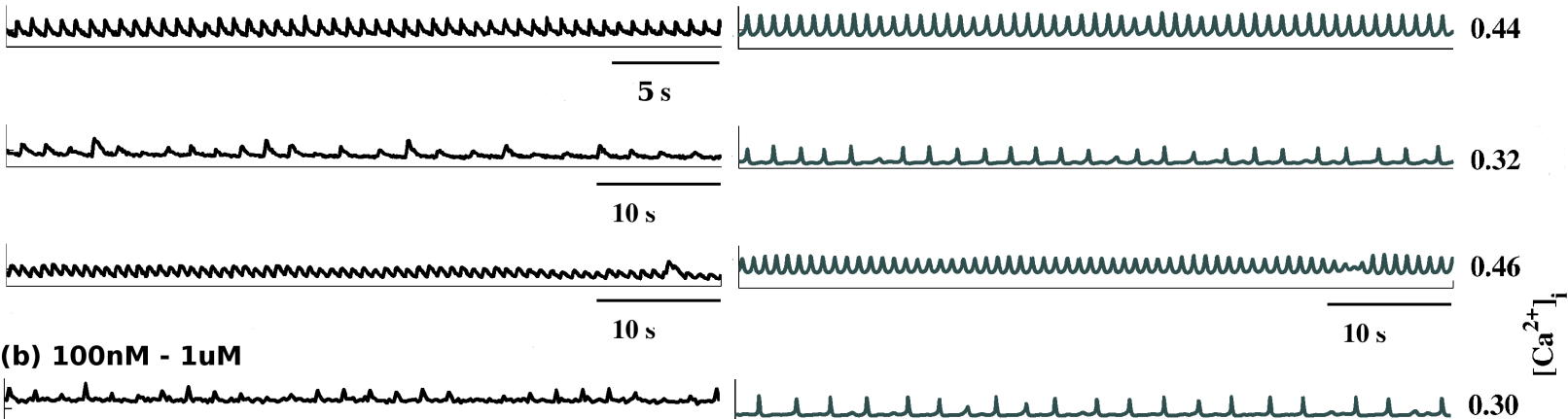

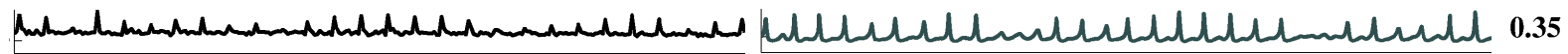

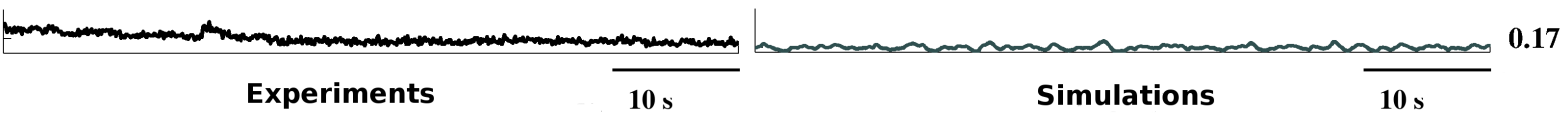

FIGURE 4. Comparison of numerical results and experimental traces for increasing concentrations of verapamil. (a) Control (no drug) and (b) $100 \mathrm{nM}-1 \mu \mathrm{M}$. For each figure, the left panel corresponds to the time amplitude series of $\mathrm{Ca}^{2+}$ fluorescence, obtained from the experiments. The right panel (grey lines) represent the time amplitude series of $\mathrm{Ca}^{2+}$ oscillations obtained with the mathematical model. The mean $\left[\mathrm{Ca}^{2+}\right]_{i}$ value (in $\mu \mathrm{M}$ ) in each scenario is given on the right hand side of each trace. 
(a)

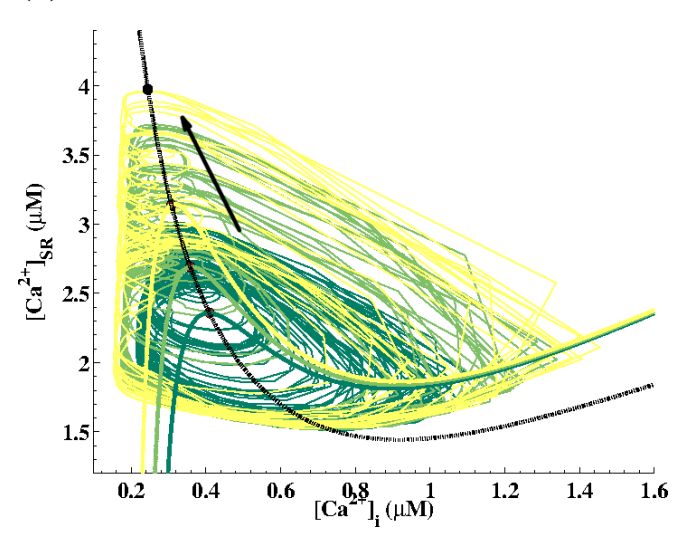

(b)

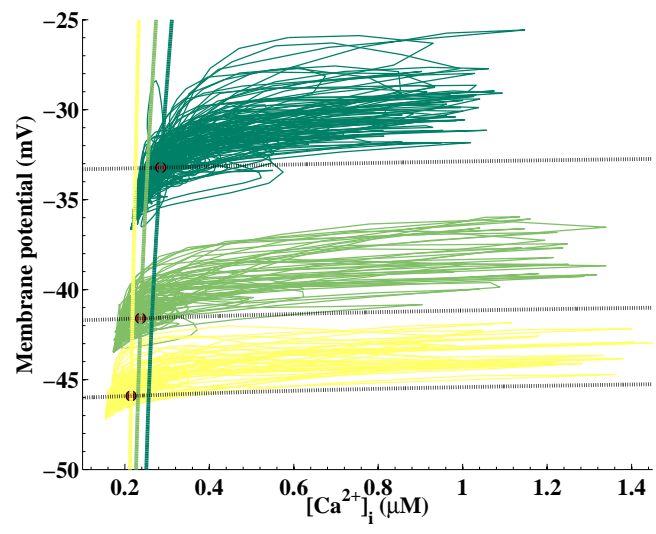

FIGURE 5. Nullcline analysis of the action of $\mathrm{Ca}^{2+}$ influx via VOCCs. Phase diagram for changes in the parameter $E_{\mathrm{Ca}}$ with (a) membrane potential held constant at $-30 \mathrm{mV}$, and (b) $\left[\mathrm{Ca}^{2+}\right]_{S R}$ held constant at $1 \mu \mathrm{M}$. From dark green to yellow $E_{C a}=18 \mu \mathrm{MV}^{-1} \mathrm{~s}^{-1}, E_{C a}=12 \mu \mathrm{M} \mathrm{V}^{-1} \mathrm{~s}^{-1}$, and $E_{C a}=2 \mu \mathrm{M} \mathrm{V}^{-1} \mathrm{~s}^{-1}$. $x$-nullclines $\left(\left[\mathrm{Ca}^{2+}\right]_{i}\right)$ are coloured according to the same pattern. Arrow shows the transition towards a stable equilibrium as $E_{C a}$ is further reduced. Results are presented for an arbitrary cell within the computational domain, and take into account coupling conditions. Assorted phase plots and equilibria are obtained for different cells, but all present the same generic characteristics.

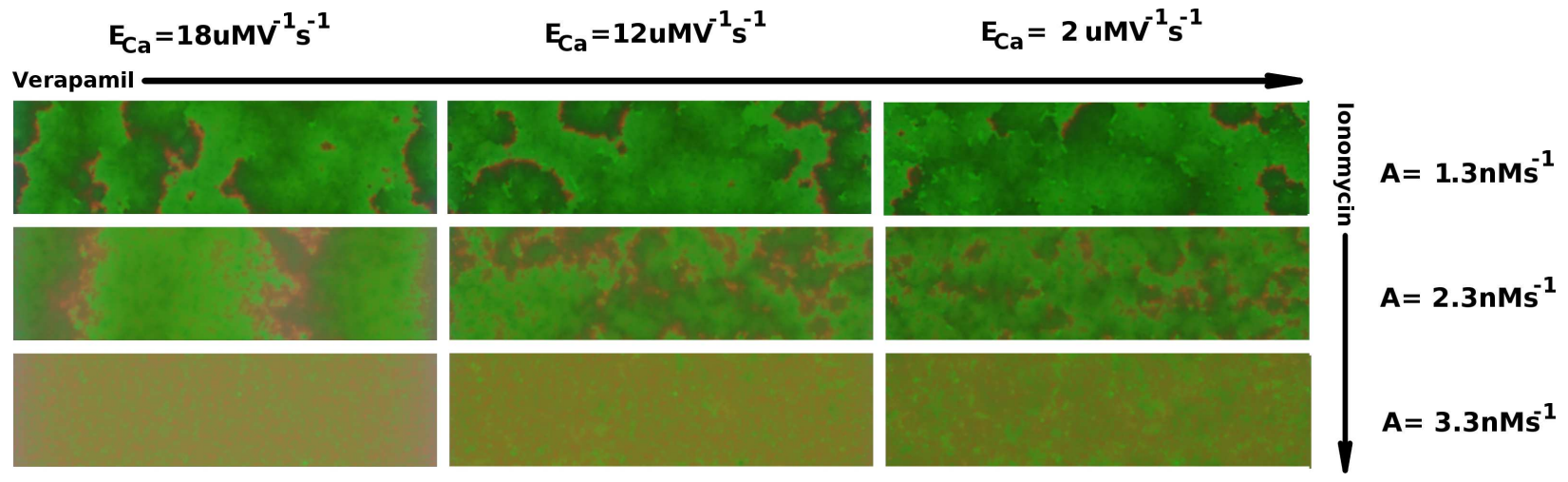

FIGURE 6. Effect of simultaneously varying $A$ (reproducing increasing concentrations of ionomycin) and $E_{C a}$ (reproducing increasing concentrations of verapamil). Transition starts from a lower value of $A=1.3 \mu \mathrm{M} \mathrm{s}^{-1}$. Coefficient of variations $\left(\mathbf{C V}_{A}\right.$ and $\left.\mathbf{C V}_{g_{C}}\right)$ and coupling conditions are identical for all figures. Red colour represent $\left[\mathrm{Ca}^{2+}\right]_{i}$, green the stored concentration $\left[\mathrm{Ca}^{2+}\right]_{S R}$, and blue the membrane potential. A purple/magenta colour is seen where red and blue strengths are equal, and therefore indicative of membrane depolarisation and high $\mathrm{Ca}^{2+}$ influx. 
$\mathrm{CV}_{\mathrm{A}}=0.01$
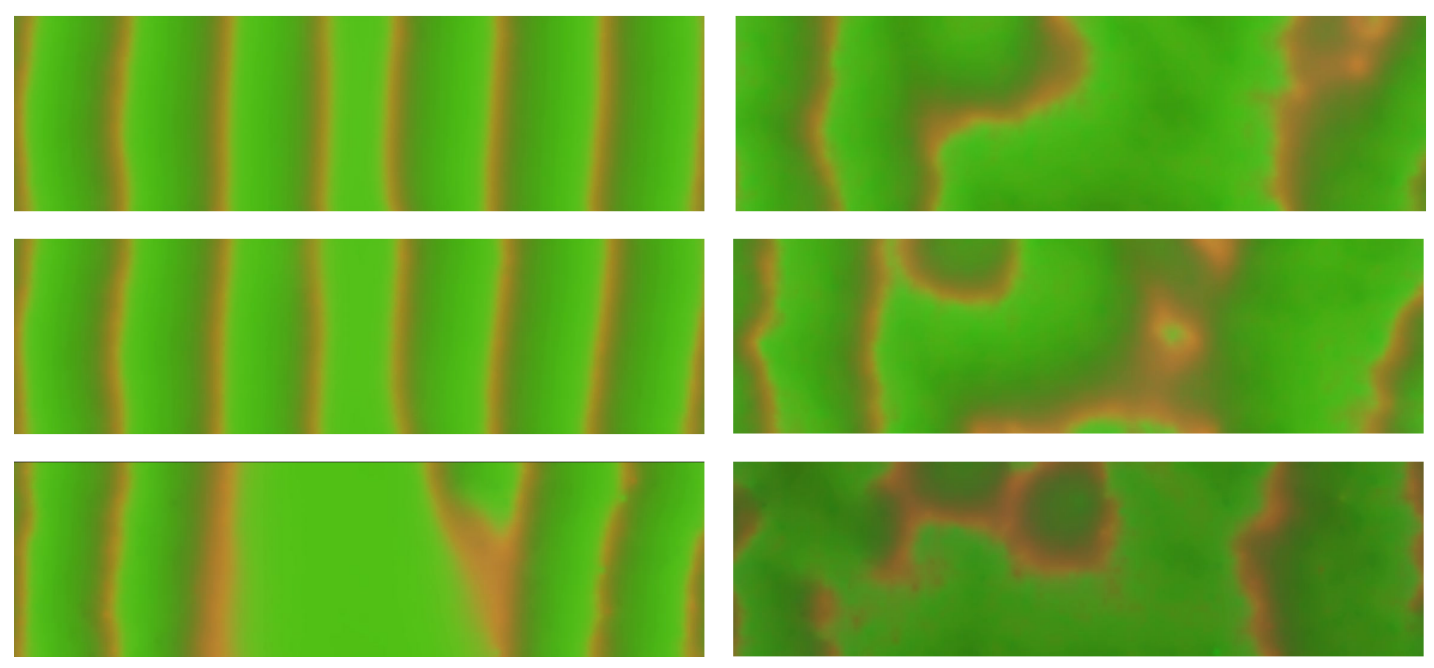

$\mathrm{Cv}_{\mathrm{A}}=0.2$
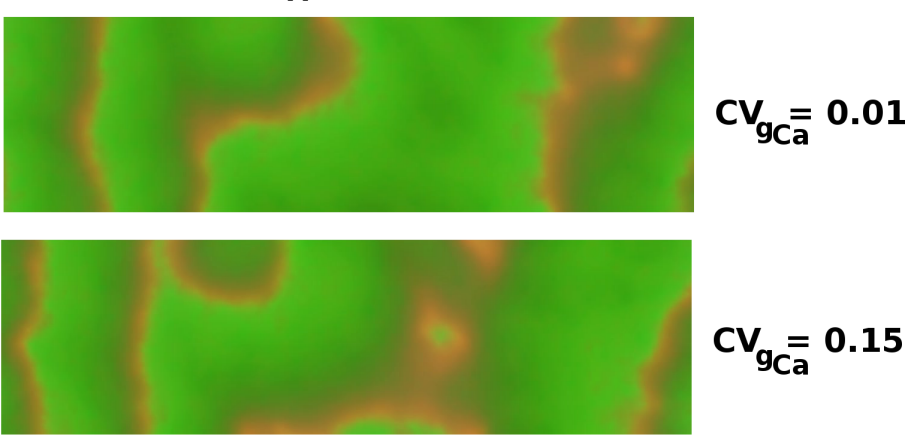

$\mathrm{Cv}_{\mathrm{gCa}}=0.3$

FIGURE 7. Effect of simultaneously varying the coefficient of variation for the $A$ distribution $\left(\mathrm{CV}_{A}\right)$ and for the $g_{C a}$ distribution $\left(\mathrm{CV}_{g_{C a}}\right)$. The mean value of $A$ is identical for all figures, and coupling is maintained at the same level. Colour coding as in Fig. 6 


\section{A APPENDIX}

\section{A.1 Mathematical Formulation}

For each individual cell, the system is described by three variables: $x=\left[\mathrm{Ca}^{2+}\right]_{i}$ represent the cytosolic free $\mathrm{Ca}^{2+}$ concentration, $\mathrm{y}=\left[\mathrm{Ca}^{2+}\right]_{S R}$ the $\mathrm{Ca}^{2+}$ concentration in the SR and $z$ the cell membrane potential.

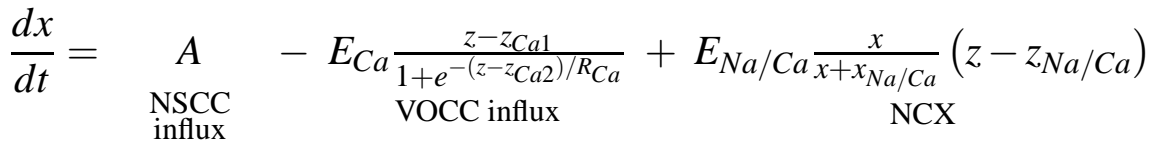

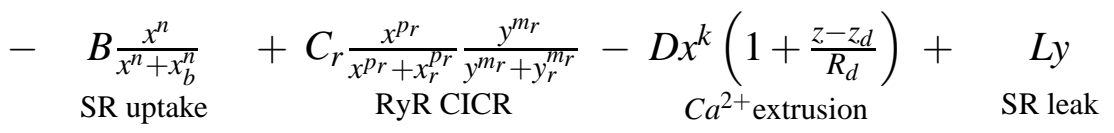

$$
\begin{aligned}
& \frac{d y}{d t}=\underset{\begin{array}{c}
B \frac{x^{n}}{x^{n}+x_{b}^{n}} \\
\text { SR uptake }
\end{array}}{C_{r} \frac{x^{p_{r}}}{x^{p_{r}+x_{r}}} \frac{y^{m_{r}}}{y^{m_{r}}+y_{r}^{m_{r}}}} \\
& \frac{d z}{d t}=-\gamma\left(E_{C l} \frac{x}{x+x_{C l}}\left(z-z_{C l}\right)+2 E_{C a} \frac{z-z_{C a 1}}{1+e^{-\left(z-z_{C a 2}\right) / R} C a}\right. \\
& \left.+E_{N a / C a} \frac{x}{x+x_{N a / C a}}\left(z-z_{N a / C a}\right)+E_{K}\left(z-z_{K}\right) \frac{x}{x+\beta e^{-\left(z-z_{C a 3}\right) / R_{K}}}\right)
\end{aligned}
$$

The electric reversal potentials with respect to $\mathrm{Ca}^{2+}$ and $\mathrm{Na}^{+}$are determined from the Nernst equation, see Parthimos et al. for details. ${ }^{29,30}$ The different terms and associated fixed parameter values can be found in Table 1. The subscript $r$ refers to RyR-mediated CICR, as opposed to $\mathrm{InsP}_{3}$-induced $\mathrm{Ca}^{2+}$ release (not included in the present formulation).

For each SMC $i$, the set of its nearest neighbours $j \in N_{i}$ consist of at most 6 neighbours, disposed at the vertices of an hexagon, depending on its position within the domain or at the boundary. Two terms:

$$
J_{C a, i}=g_{C a} \sum_{j \in N_{i}}\left(x_{j}-x_{i}\right) \quad V_{m, i}=g_{z} \sum_{j \in N_{i}}\left(z_{j}-z_{i}\right)
$$

are added to (A-1a) and (A-1c), respectively, to model $\mathrm{Ca}^{2+}$ and electrical coupling. 


\section{List of Tables}

1 Terms and coefficients associated with the system of equation $\ldots \ldots$. . . . . 22 
TABLE 1. Terms and coefficients associated with the system of equation

\begin{tabular}{|c|c|c|}
\hline \multicolumn{2}{|c|}{ Parameter Description } & \multirow{2}{*}{$\frac{\text { Value }}{\text { variable }}$} \\
\hline$A$ & $\mathrm{Ca}^{2+}$ influx via NSCC & \\
\hline$L$ & SR leak rate constant & $0.025 \mathrm{~s}^{-1}$ \\
\hline$\gamma$ & scaling factor (inversely related to cell capacitance) & $1 \mathrm{~V} \mu \mathrm{M}^{-1}$ \\
\hline \multicolumn{3}{|c|}{ VOCC influx } \\
\hline$E_{C a}$ & whole cell conductance & variable \\
\hline$z_{C a 1}$ & reversal potential & 0.12 to $0.135 \mathrm{~V}$ \\
\hline$z_{C a 2}$ & half point of activation sigmoid & $-0.024 \mathrm{~V}$ \\
\hline$R_{C a}$ & max. slope of activation sigmoid & $0.0085 \mathrm{~V}$ \\
\hline \multicolumn{3}{|l|}{ NCX } \\
\hline$E_{\mathrm{Na} / \mathrm{Ca}}$ & whole cell conductance & $43.8 \mu \mathrm{M} \mathrm{V}^{-1} \mathrm{~s}^{-1}$ \\
\hline$z_{\mathrm{Na} / \mathrm{Ca}}$ & reversal potential & -0.03 to $-0.045 \mathrm{~V}$ \\
\hline$x_{\mathrm{Na} / \mathrm{Ca}}$ & half point of $\mathrm{Ca}^{2+}$ activation & $0.5 \mu \mathrm{M}$ \\
\hline \multicolumn{3}{|c|}{ SR uptake } \\
\hline$B$ & rate constant & $400 \mu \mathrm{M} \mathrm{s}^{-1}$ \\
\hline$x_{b}$ & half point of ATPase activation sigmoid & $4.4 \mu \mathrm{M}$ \\
\hline$n$ & Hill coefficient & 2 \\
\hline \multicolumn{3}{|c|}{ RyR CICR } \\
\hline$C_{r}$ & rate constant & $1250 \mu \mathrm{M} \mathrm{s}^{-1}$ \\
\hline$y_{r}$ & half point of $\mathrm{Ca}^{2+}$ efflux sigmoid & $8.9 \mu \mathrm{M}$ \\
\hline$x_{r}$ & half point of CICR activation sigmoid & $0.9 \mu \mathrm{M}$ \\
\hline$m_{r}$ & Hill coefficient & 2 \\
\hline$p_{r}$ & Hill coefficient & 4 \\
\hline \multicolumn{3}{|c|}{$\mathrm{Ca}^{2+}$ extrusion by ATPase pump } \\
\hline$D$ & rate constant & $6.25 \mu \mathrm{M} \mathrm{s}^{-1}$ \\
\hline$z_{d}$ & intercept of voltage dependence & $-0.1 \mathrm{~V}$ \\
\hline$R_{d}$ & slope of voltage dependence & $0.25 \mathrm{~V}$ \\
\hline$k$ & exponent for $\left[\mathrm{Ca}^{2+}\right]_{i}$ dependence & 2 \\
\hline \multicolumn{3}{|c|}{$\mathrm{Cl}^{-}$channels } \\
\hline$E_{C l}$ & whole cell conductance & $65 \mu \mathrm{M} \mathrm{V}^{-1} \mathrm{~s}^{-1}$ \\
\hline$z_{C l}$ & reversal potential & $-0.025 \mathrm{~V}$ \\
\hline$x_{C l}$ & $\mathrm{Ca}^{2+}$ sensitivity & $0 \mu \mathrm{M}$ \\
\hline$k$ & exponent for $\left[\mathrm{Ca}^{2+}\right]_{i}$ dependence & 2 \\
\hline \multicolumn{3}{|c|}{$\overline{K^{+} \text {efflux }}$} \\
\hline$E_{K}$ & whole cell conductance & $43 \mu \mathrm{M} \mathrm{V}^{-1} \mathrm{~s}^{-1}$ \\
\hline$z_{K}$ & reversal potential & $-0.095 \mathrm{~V}$ \\
\hline$z_{C a 3}$ & half point of $K_{C a}$ channel activation sigmoid & $-0.027 \mathrm{~V}$ \\
\hline$R_{K}$ & max. slope of $K_{C a}$ channel activation sigmoid & $0.012 \mathrm{~V}$ \\
\hline$\beta$ & $\mathrm{Ca}^{2+}$ sensitivity of $K_{C a}$ channel activation sigmoid & $0 \mu \mathrm{M}$ \\
\hline
\end{tabular}

